\title{
Presentation of Undergraduate Research-oriented Teaching Process
}

\author{
Qiu-feng SHANG \\ Department of Electronics and Communication North China \\ Electric Power University \\ Baoding, China \\ lindashqf@126.com
}

\begin{abstract}
Research-oriented teaching can train students' ability of analyze and design and skills of design and development. This paper shows the process of the researchoriented teaching by the demonstration of an experimental case. Literature review and topic selection, theoretical analysis, system design and simulation experiment are included in research-oriented teaching. The evaluation of the researchoriented teaching course uses the whole process evaluation mechanism. It can provide reference for the undergraduate course teaching through the experimental case demonstration.
\end{abstract}

Keywords-Research-oriented teaching; experimental case; evaluation mechanism

\section{INTRODUCTION}

Research-oriented teaching requires teachers to treat the teaching process with the attitude of research, to refine the basic knowledge, to concise design projects, to train students' ability of analysis and research and skills of design and development .Research-based teaching requires students to experience success, develop, enjoy and use the correct cognition and positive emotions from passiveness to interaction, from dependence to independence, from acceptance to creativity ${ }^{11]}$.

Taking the curriculum DSP system design for the Electronic Information Science and Technology specialty of North China Electric Power University as an example, the process of research-based teaching was demonstrated through a teaching case.

\section{LITERATURE REVIEW AND TOPIC SELECTION}

The orientation of the curriculum decides the level of research.it is the highest level of research-oriented teaching to make students interested in the subject so as to transcend the constraints of classroom and textbook in the course of teaching. At the beginning of the course, the teacher introduces the main topics of DSP application through the overview of DSP development, and groups students to retrieval literature in different thematic areas. Expand the horizons of students, stimulate students' learning interest and seek design subjects through the literature review ${ }^{[2]}$.

By referring to the literature [3-8], the group selects the

Education reform funds of North China Electric Power University

\author{
LIU Wei \\ Department of Electronics and Communication North China \\ Electric Power University \\ Baoding 071003, China \\ 1007759705@qq.com
}

vibration characteristics of the transformer winding to be verified. The vibration characteristics of transformer winding are as follows:

1).The winding vibration signals are mainly concentrated in the $100 \mathrm{~Hz} .200 \mathrm{~Hz}, 300 \mathrm{~Hz}$ and $400 \mathrm{~Hz}$ are also distributed. The winding vibration signals are almost zero beyond $1000 \mathrm{~Hz}$

2).The amplitude of the winding fundamental frequency and the square of the load current satisfy the linear relationship.

3).The change of the winding pre-tightening force can affect the natural frequency of the winding. When the natural frequency of the winding is close to the frequency of electromagnetic force, the resonance will be triggered, which should be avoided.

The first vibration characteristics of the transformer winding are studied by choice.

\section{THEORETICAL ANALYSIS}

For the transformer winding with load current, according to Biot - Savart law, assuming the electric power acting on the current element is $d F=\delta d V B$, the electric force acting on the winding is:

$$
F=\int \delta d V B
$$

The magnetic induction intensity is generated by all current elements, having the positive proportional relationship with the current:

$$
B=\frac{\mu}{4 \pi} \int \frac{\delta d V r^{0}}{r^{2}}
$$

It can be inferred from the formula (1) and formula (2) that the electromagnetic force acting on the transformer winding is proportional to the square of the load current. The winding vibration acceleration is proportional to the electromagnetic force, so the amplitude of winding vibration acceleration and the square of the load current satisfy the linear relationship. According to the first characteristic, winding vibration signal is mainly concentrated in the $100 \mathrm{~Hz}$, so the fundamental frequency magnitudes of winding 
vibrations and the square of the load current satisfy the linear relationship.

In practical application, the linear relationship can be used to diagnose whether there is abnormal vibration of transformer winding. If the transformer winding vibration is abnormal, the vibration amplitude should not satisfy the linear relationship.

\section{SYSTEM DESIGN}

The system of winding vibration signal acquisition and analysis designed in this paper is shown in figure 1.

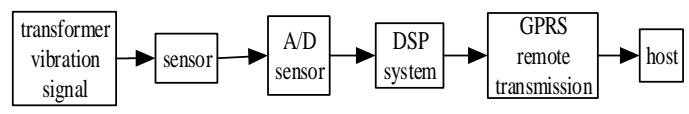

Fig.1 Block diagram of winding vibration signal acquisition and analysis system

The physical vibration signal of the transformer can not be analyzed and processed directly in the circuit. It must be converted to a voltage signal by the voltage output type acceleration sensor according to certain laws. And then the analog signal is converted into digital signal by the analog to digital converter and transmitted to the DSP system. Spectrum analysis of vibration signal is made inside the DSP system. Winding fault can be judged according to the difference degree between the vibration amplitude of fundamental frequency and criterion. The processing results are sent to the GPRS module, and then are sent remotely to the host by GPRS module.

\section{SIMULATION EXPERIMENT}

The digital conversion, signal processing and SPI communication modular of the winding vibration signal acquisition and analysis system can be simulated based on the TMS320VC5509 experimental box.TMS320VC5509 experimental box diagram is shown in figure 2 .
Fig.2 TMS320VC5509 experimental box diagram

TMS320VC5509 is the core of the system control and processing. There is an A/D on the chip which can complete the internal A/D conversion function. The Fast Fourier Transform of signal can be completed in real time. The frequency structure of the signal can be got by the spectrum analysis. The McBSP of DSP experimental box is set to SPI communication mode.TMS320VC 5509 will send the transform results to the GPRS module through the serial port. The spectrum analysis results are sent to GPRS module remotely and displayed on the host.

Members of the group work in cooperation with the design of signal acquisition and processing program and the design of SPI communication program respectively.

\section{A. Signal Acquisition and Processing Program Design}

$\mathrm{A} / \mathrm{D}$ conversion is initiated by the interrupt trigger mode and then the data is read. The sampling frequency is

determined by the timer interrupt. The fast Fourier transformation (FFT) is made for the data after analog to digital conversion, taking advantage of DSP powerful computing functions for spectrum analysis inside the DSP. The difference degree between the vibration amplitude of fundamental frequency and criterion is calculated according to the spectrum characteristic, and compared with the safety range for winding fault diagnosis .The program design flow is shown in figure 3.

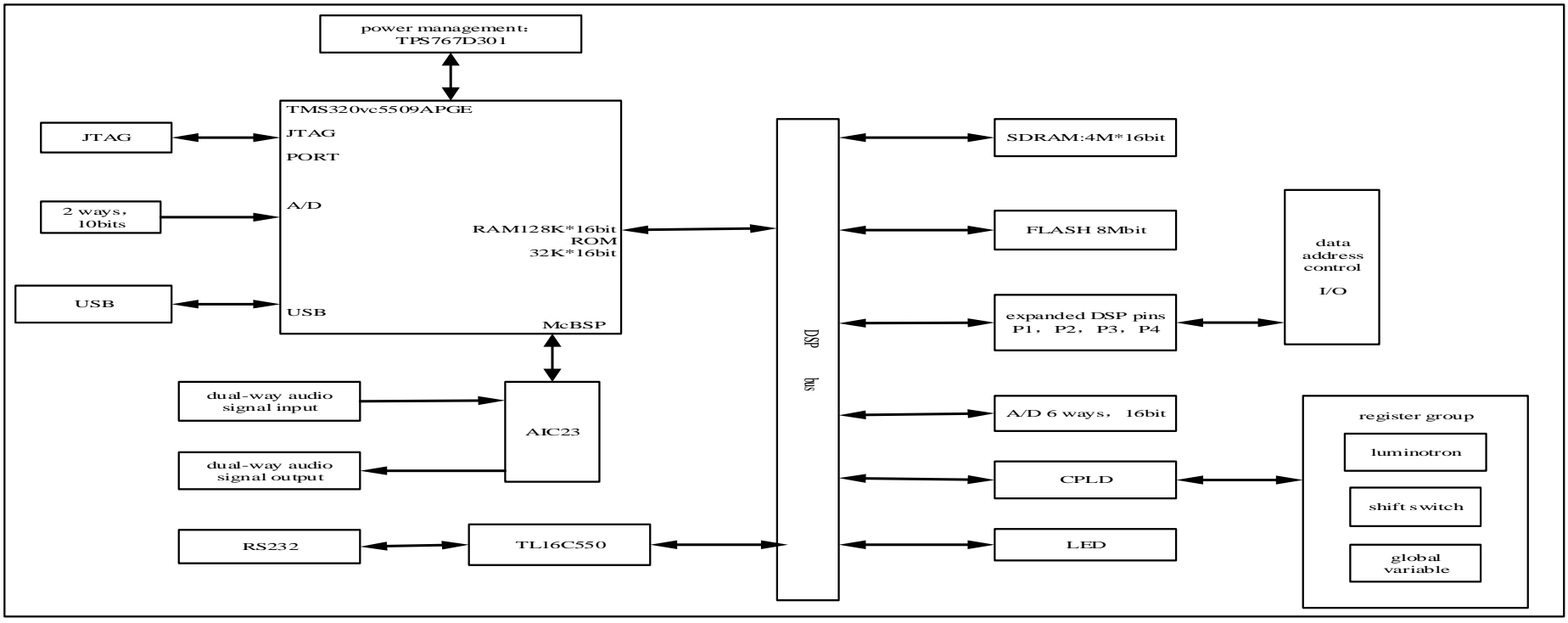




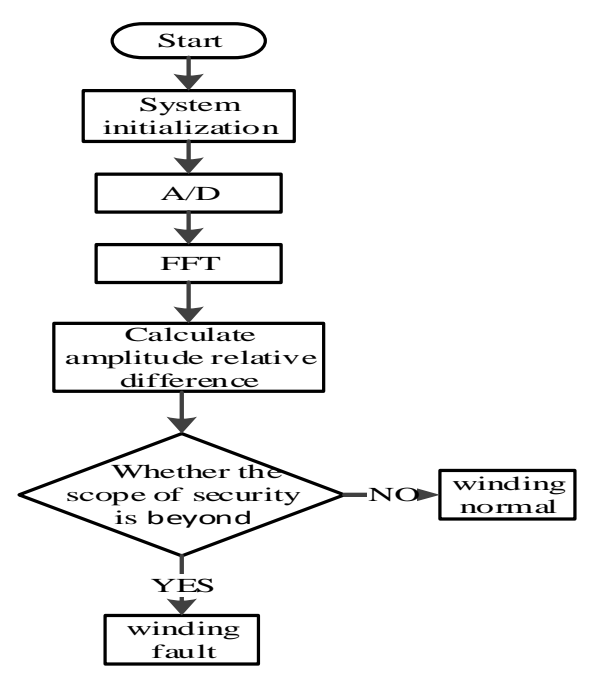

Fig.3 Signal acquisition and processing program design flow chart

\section{B. SPI communication program design}

SPI is a serial communication protocol with simple communication principle, working in a master-slave mode. This model usually has a master device and one or more slave devices. Three lines are needed for communication, namely SDI (data input), SDO (data output), SCLK (clock), CS (chip selection).The clock pulse is provided by SCK. SDO and SDI complete data transmission based on the pulse. Data is outputted through the SDO line. The data changes along with the clock rising edge or falling edge, and in following clock falling edge or rising edge is read.

Since there is no GPRS module in the experimental box, after configuring the SPI mode, the students judge whether the transmission function is normal based on self-sending and self-receiving of SPI.SPI communication program design flow chart is shown in Figure 4.

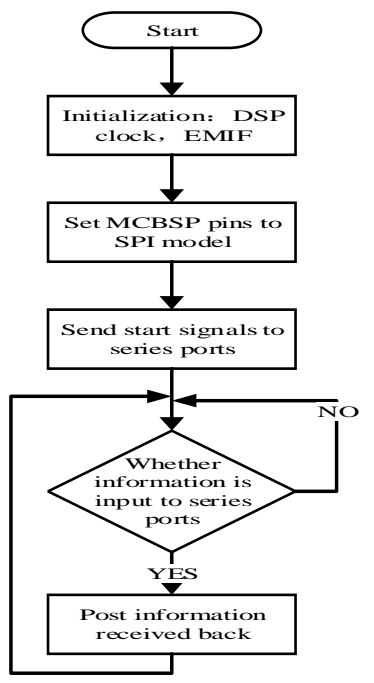

Fig.4 SPI program design flow chart

\section{PERFORMANCE EVALUATION}

The course performance is unified evaluated by the combination of literature review report, class discussion and demonstration, practice performance, comprehensive design report and interview.

Periodic effects of teaching can be effectively feedback by process evaluation mechanism. Evaluations not only stay in assessment for students, but also can promote teachers to adjust teaching contents and plans. Class discussion and practice demonstration not only deepen the student's thinking, but also stimulate students interest in learning through the deep exploration activities. Evaluation scores are based on students' autonomous degree and exploration depth, not rigidly adhering to the clear answer of knowledge test, focusing on thinking training, encouraging innovative thinking and encouraging students to analyze learning process.

\section{SUMMARY}

The teaching case shows the teaching process to carry out practical research-oriented teaching. In the whole teaching process, the students independently refer to the literature, choose the subject, design system for experimental study and exercise the ability to study and reference for the

undergraduate research. The teaching case provides a research-oriented teaching [9].

\section{ACKNOWLEDGMENT}

This research was financially supported by Education reform funds of North China Electric Power University.

\section{REFERENCES}

[1] Fan MENG, Analysis of the basic characteristics of under graduate research teaching, J. MEITAN Higher Education. Vo 1.27,No.6 (2009.11): 31-33.

[2] You-qing CHEN, Qiong WU, Lecturing to promote students exploration-change of lecturing in college research-based teaching, J. Journal of Higher Education. Vo 1.32,No.10 (2011.10): 94-99.

[3] HONG Gang.Study on State Monitoring and Fault Diagnosis of Transformer Winding and Core Based on Vibration Analysis[D].Xi'an University of Technology,2010

[4] XU Zhi.Study of Transformer on-Line Monitoring Based on Vibration[D],Chongqing University, 2010

[5] HONG Kaixing Reasearch on Power Transformer Status Detection and Fault Diagnosis Based on Vibration Method[D].Zhejiang University, 2010.

[6] YU Haiqiang.Study on State Monitoring of Transformer on Vibration Analysis[D].Xihua University,2012.

[7] JI Shengchang.Research on vibration characteristics of transformer windings and core and its application in fault monitoring[D].Xi'an Universit,2003

[8] YUAN Guogang,XIE Po’an,XIE Bo,HAN Xuehua.Influence of Axial Precompression on the Vibration of Transformer Windings[J].Noise and vibration control,2003,(2):25-27.

[9] Stark,J.S., Lattuca,L.R. Shaping the College Curriculum: Academic Plans in Action[M]. Massachusetts: Allyn and Iscan, 1997.. 